\title{
ESPACIO DE JUAN RAMÓN JIMÉNEZ: ORGANIZACIÓN DE UNA OBRA
}

\author{
Andrés Morales Milohnić \\ Universidad de Chile \\ Universidad Finis Terrae \\ andresmoralesmilohnic@hotmail.com
}

Palabras Clave: literatura española, poesía contemporánea, poema en prosa, Juan Ramón Jiménez.

KEY WORDS: spanish literature, contemporary poetry, poem in prose, Juan Ramón Jiménez.

Al maestro y amigo, profesor Eduardo Godoy Gallardo,
con mi admiración y agradecimiento

Escasa es la crítica en torno al último período creativo de Juan Ramón Jiménez. Escasas son, también, las ediciones que han recuperado o han divulgado, para el público general o especializado, los poemas, las prosas o proyectos del gran poeta español ${ }^{1}$.

A mi parecer, la Obra de Juan Ramón adquiere otra perspectiva desde la lectura de su poesía última: lo que antes podría aparecer como inconexo logra conectarse, lo que,

${ }^{1}$ Solo un pequeño puñado de ediciones circulan en España, destacando, por sobre todas las demás, la realizada por una de las máximas especialistas en este poema, Aurora de Albornoz, publicado por Editora Nacional en Madrid en 1982 y la edición de Ángel Crespo y Pilar Gómez Bedate de la indispensable Antolojía Jeneral (sic.) en prosa 1898-1954 (1981). En Hispanoamérica, este período de Juan Ramón Jiménez es casi desconocido, por lo que, creo, se hace urgente actualizar las antologías y reediciones de su obra poética, fundamentalmente para que el público valore al autor como un poeta esencial de la lengua castellana y no solo como aquel que solo escribiera el conmovedor Platero y yo. 
tal vez, se leía como hermético abre su contenido al lector atento. Creo, sin exagerar, que la poesía de este autor queda entre las pocas cumbres de la literatura occidental, pues, como explicaré más adelante, adquiere un tono profético y hasta filosófico que en mucho lo alejan de llamado "regionalismo" del que fuese acusado (y que él no desmentía pues es éste uno de los filones más productivos de su poesía) o, peor aún, de ser un escritor distanciado de los problemas terribles de su tiempo o de las innovaciones formales de la nueva poesía (otra acusación sin fundamentos que demuestra la deficiente lectura de críticos y poetas en torno a esta etapa de su obra).

El texto que servirá de base para los conceptos aquí desarrollados es el largo poema en prosa, dividido en tres partes, Espacio ${ }^{2}$. Texto que, como bien señala Aurora de Albornoz (Albornoz, Espacio), será el centro articulador de un proyecto inconcluso que el autor dejase al sobrevenirle la muerte, un ambicioso proyecto reestructurador de toda su última producción titulado En el otro costado.

\section{EL CONCEPTO DE OBRA EN EL OTRO COSTADO}

Es bien sabido por los seguidores de la poesía de Juan Ramón Jiménez que su concepto de Obra (así, con mayúsculas) es primordial a la hora de entender y penetrar en la sutileza de su palabra. Desde 1917, cuando publica su Diario de un poeta reciéncasado (sic.) ${ }^{3}$, se inicia por parte del propio autor una reelaboración de toda su poesía, un salto hacia lo esencial, una búsqueda que algunos han llamado de la "poesía pura", pero que hoy bien podría afirmarse como "intermedia" 4 . Así, y siguiendo la denominación del autor andaluz, su primera época será aquella que va desde sus primeras publicaciones en forma de libro -Ninfeas y Almas de Violeta (ambas de 1900)- hasta su ya famoso Diario de un poeta reciéncasado, período señalado (por Juan Ramón) y conocido como el de los "Borradores silvestres". Para la crítica, entonces, existirán dos etapas o momentos en la producción del autor. Una primera de inspiración modernista (los "Borradores") y otra cercana a la "poesía pura", que se iniciará con sus libros publicados en 1917 hasta sus últimos textos. Solo algunas voces, a las que me agrego, han complementado esta mirada sobre la poesía juanramoniana distinguiendo un "tercer momento" en su itinerario poético, justamente aquel que comprende textos como Espacio (1941-1942-1954), Romances de Coral Gables (1948) y Animal de fondo (1949), la producción casi desconocida de su última etapa, aquella que, precisamente, se estructura como su proyecto inconcluso,

2 Es importante señalar que el autor inicia la escritura del poema en 1941, lo continúa en 1942, publica el "Fragmento Primero" (dedicado a Gerardo Diego) en 1943 (en la prestigiosa revista "Cuadernos Americanos" de México) y lo finaliza en 1954.

${ }^{3}$ En este trabajo se respetará el particular uso ortográfico del poeta.

${ }^{4}$ La llamo "Intermedia" por las posibles diferencias (aunque existen muchas semejanzas) que pueden existir entre la "poesía pura" francesa, iniciada por Stéphane Mallarmé y cuyo máximo representante es Paul Valéry. 
En el otro costado. Se hace urgentísimo actualizar los períodos que intentan "contener" su obra, visualizando su escritura, insisto, desde su última etapa y, subrayo con énfasis, entendiendo que toda su poesía, desde 1917 en adelante es, desde esta perspectiva, un todo casi indivisible e inclasificable o desmenuzable. Aún así, conviene señalar los tres estadios que, a mi entender, hacen más fácil la entrada (y sólo con fines didácticos) a la producción del poeta. De esta forma se pueden distinguir tres "momentos":

Primer Momento. Conocido tradicionalmente como el de los "Borradores silvestres", es decir, toda su producción entre 1900 y 1916 y que posee una insoslayable influencia del Modernismo.

Segundo Momento. Llamado de la "Poesía Pura", pero que podría señalarse (si es que cabe etiquetar algo en poesía) como de "poesía esencial", "poesía madura" o bien, "Momento intermedio".

Tercer Momento. No reconocido siempre por la crítica tradicional y que se generaría a partir del poema Espacio (que es lo que postulo aquí). Y del proyecto de libro que reuniría toda su última producción, En el otro costado. Período, por decir lo menos, complejo, pues el propio autor reclasifica toda su obra, prosifica poemas en verso (Espacio es el mejor ejemplo) y articula su producción en torno a tres Antolojías (sic.) donde, muchas veces, se eliminan textos anteriores o se modifican y cambian casi completamente de sentido, siempre tendiendo a la "poda" más que a la "summa". Este "Tercer Momento" o etapa hay que situarlo desde 1941, fecha en que Jiménez inicia la escritura de Espacio, hasta el momento de su muerte, en el año 1958.

Vista su "Obra" desde esta perspectiva, es menester caracterizar el período que hoy aquí interesa, intentando conceptualizar fundamentalmente el núcleo ideológico que existe tras el proyecto del libro En el otro costado. De esta manera, la idea central tras este proyecto, que puede entenderse como "concepto", es el de la "unidad total". Quizás puede aparecer como extremadamente complejo y ambicioso, pero que responde muy bien a uno de los principios fundamentales de Juan Ramón Jiménez, esto es, el de articular, entramar o entretejer toda su "Obra" como un solo poema, como un solo texto que pudiese dar cuenta del mundo desde su especial mirada y que, además, fuese a esa hermosa idea que manifestara el autor en más de una ocasión: "ser poesía más que poeta".

La idea de unidad de toda su poesía es acariciada por Jiménez durante casi toda su vida y cuando en 1917 se inicia, en sus propias palabras "su verdadera escritura", sus libros, por heterodoxos que puedan parecer, van buscando un "todo", un registro, un temple que, inevitablemente, habrían de encaminarlo hacia la escritura que ejecutó durante los últimos años de su vida. Es en el año 1941 cuando el poeta siente una necesidad imperiosa por dar una unidad a su escritura, como si se tratase de una gran sinfonía o de un texto musical de largo aliento. A partir de un severo tratamiento en una clínica psiquiátrica en los Estados Unidos (uno de los muchos que sufrió a lo largo de su vida y que intentaron darle ánimos y sacarlo de depresiones agudísimas en las que caía con frecuencia) aparece el concepto de un poema como "dictado" y de "Arte Mayor". En 
carta dirigida a Enrique Díez-Canedo (del 6 de agosto de 1943)5 Juan Ramón señala la génesis del poema Espacio y también de lo que, posteriormente, esbozaría como En el otro costado:

“(...) Pues en 1941, saliendo yo, casi nuevo, resucitado casi, del hospital de la Universidad de Miami (...) una embriaguez rapsódica, una fuga incontenible empezó a dictarme un poema de espacio, en una sola estrofa de verso mayor (...)"

Esta “embriaguez rapsódica" que menciona el poeta será, sin duda, el camino que seguirá sus próximos años. En 1943 saldrá a la luz en "Cuadernos Americanos" de México (Vol. XI, número 5, septiembre-octubre de 1943) el primer fragmento de Espacio, eso sí, en verso (todavía no prosificado por el autor) y con el título de Espacio (Fragmento Primero de la Segunda Estrofa). Cantada. Varios años tardará Jiménez en dar a la luz los dos fragmentos restantes, de igual forma, varios años tardará en darle su carácter actual, es decir, como "poema en prosa".

Pero el concepto de unidad, a partir de la citada "embriaguez" y del poema Espacio, fluirá en el poeta como único horizonte para concebir su "Obra". De esta forma, planeará un "macro libro" titulado Lírica de una Atlántida (proyecto inconcluso también y que debería contener, a su vez, al libro En el otro costado) y el texto homónimo que contendría el poema Espacio. En síntesis, En el otro costado se constituiría de cinco partes:

\section{Mar sin caminos \\ II. Canciones de La Florida \\ III. Espacio \\ IV. Romances de Coral Gables \\ V. Caminos sin mar}

Todo entendido como agrupando y conteniendo a lo otro 7 . Un sistema de "cajas chinas" o de "matrioshkas rusas" donde una unidad abarca, posee, contiene a la otra unidad. Así todo se ordena como sigue: Espacio (poema "motor", nuclear, generador) contenido en y centro de En el otro costado. En el otro costado contenido en Lírica de una Atlántida. Lírica de una Atlántida contenido es su proyecto mayor en su proyecto de Obra. Todo

${ }^{5}$ Citada en el Estudio de la Obra de la edición de Espacio por Aurora de Albornoz (65).

${ }^{6}$ Testimonio de lo afirmado es la grabación del poema (solo del "Fragmento Primero" y otros textos en verso) que hiciera Juan Ramón, para la Biblioteca del Congreso de los Estados Unidos, luego editada en forma de disco de vinilo y que posee evidentes diferencias con la versión final. Al oír las pausas versales, se puede afirmar con certeza que aún se trata de la escrita en verso. Años más tarde (1995) Editorial Visor reeditará la grabación en forma de Compact Disc conjuntamente con una Antología Personal del poeta (sobre la base de la selección realizada para la grabación norteamericana).

${ }^{7}$ Como también agrupado y contenido en lo otro. 
es a todo, diría alguno, el todo y las partes unidas sin posibilidad de concebir a la una sin la otra. Juan Ramón señalará en el "Fragmento Primero" de Espacio:

“(...) El mar no es más que gotas unidas, ni el amor que murmullos unidos, ni tú, cosmos, que cosmillos unidos. Lo más bello es el átomo último, el solo indivisible, y que por serlo no es ya más pequeño. Unidad de unidades es lo uno (...)" (Jiménez, Espacio 19).

Todo unido en su diversidad. Utilizando, tal vez sin querer, el concepto, de por sí vanguardista, de "fragmento" como unidad. Fragmento relacionado con el todo, poema relacionado con la Obra. De esta manera, nada es despreciable, todos los elementos, las partes, las palabras, hasta las sílabas (en su silencio, en su musicalidad) guardan un sentido de unidad y de estructura, son, al fin de cuentas, el todo. Por otro lado, este todo poético no existiría sin cada uno de sus fragmentos, de las piezas de este admirable reloj que funciona a la perfección, describiendo el mundo, sobre todo, reflexionando en torno a él y en torno a la poesía. Internándose en el tema del amor, en el tema de la muerte y casi en todos los tópicos que pueden asociarse a la gran poesía. Así entonces, es necesario entender este "principio de unidad", este concepto de unidad como el "eje estructurador" de En el otro costado y, obviamente, de Espacio (a pesar de la multiplicidad de elementos tratados en el poema y, aunque suene a contradicción, gracias a ellos también).

\section{UNA LECTURA DE LA DIVERSIDAD: LOS TEMAS DEL “FRAGMENTO PRIMERO” DE ESPACIO}

Una vez revisado el concepto de unidad en el "libro-proyecto" En el otro costado, es indispensable registrar cómo funciona este principio estructurador en el poema "generador" del libro, Espacio. De esta manera será posible entender el procedimiento poético del autor en sus últimos años de producción y, también, observar cómo opera esta idea de fragmentación y unidad; de parte y todo en la obra de Juan Ramón.

En una primera lectura del "Fragmento Primero" de Espacio ${ }^{8}$ lo que llama inmediatamente la atención del lector es el fluir del discurso, su complejidad (a pesar de la aparente simplicidad del mismo) y la multiplicidad de temas o tópicos que el hablante asume a la hora de tratar la "realidad interna" (la del hombre, la del poeta, la del enamorado) y la "realidad externa" (la del mundo). Tras la perplejidad que esto produce en el lector, aparece también una idea clara: este texto es, indudablemente, la quintaesencia de la producción juanramoniana. Aquí, el poeta ha abandonado cualquier "oropel" modernista, si cabe el término. Cualquier posible vicio escritural o cualquier

8 Por razones de extensión no ejemplificaré con el "Fragmento Segundo" ni con el "Fragmento Tercero", aunque debe entenderse que éstos poseen características muy similares, sino iguales, en lo que se refiere a temas y procedimientos. 
fatuidad es dejada de lado para que la conciencia fluya casi directamente, sin que cualquier recurso del estilo entorpezca la comprensión de lo tratado. Al mismo tiempo, es inevitable hacer asociaciones literarias y pensar en un poeta que ha asumido todos los aportes, los hallazgos y las innovaciones que se han producido a lo largo de los cincuenta primeros años de la literatura occidental del siglo veinte en los distintos momentos de la composición -o escritura- del poema. Son insoslayables, los vínculos con la corriente de la conciencia, con los recursos del monólogo interior que fundara James Joyce; con la fragmentariedad (y unidad) de los diversos cantos del poema y libro Altazor de Vicente Huidobro; con la metáfora cubista o creacionista; con el Surrealismo (que por momentos podría señalarse como asumido en algunos pasajes en que el discurso se "abandona" en una suerte de escritura automática, ya sea a través de la enumeración caótica o la presencia de lo onírico como elemento fundamental). Igualmente, y no en menor proporción, aunque felizmente integrada, hay una vocación por constituirse en un texto clásico, en un poema que, incorporando todos los procedimientos arriba enumerados, a pesar de todo, no se deja llevar totalmente por ninguno de ellos en exclusividad y, a cada paso del discurso, nos hace saber que no es el "continente" sino el "contenido" lo que es primordial y necesario visualizar. Desde este principio es que propongo leer el poema: donde el hablante será siempre el eje estructurador (como en toda la poesía propiamente lírica), pero donde no solo aparece una visión impresionista o una proyección del yo (en su mirada, en su crítica, en su nostalgia por el terruño perdido después de la guerra civil) sino que emerge poderosamente una conciencia reflexiva que construirá un punto de vista (ese átomo último) que irá meditando sobre la realidad y que, sin ambigüedades, conducirá al lector hacia "su forma" de ver las cosas y hacia sus preocupaciones y temas.

Estos temas hablarán de la riqueza y de la diversidad de asuntos que le interesaban a Juan Ramón Jiménez. Del compromiso del poeta con el humanismo, con la naturaleza (en una profética visión ecologista, cuando este asunto aún no era un tema importante en la sociedad), en fin, con los terribles sinsabores y consecuencias que tuvieron para el propio autor el exilio o "transtierro", la guerra civil y las dos guerras mundiales, los totalitarismos, el posible exterminio del ser humano (luego de la explosión de la bomba atómica en Hiroshima), la lejanía (o el espacio que falta) y la saudade casi enfermiza (el espacio construido en el poema).

Este último tópico, el del espacio, será el más importante e ineludible. Tal como lo señala el título del poema, la lejanía crea un "espacio externo" (el de la distancia) y un "espacio interno" (el del amor y el de la poesía). El poeta escribe desde "el otro costado", desde América, desde el otro lado del Atlántico. El texto pretende anular ese espacio, quiere hacer más cercanas las orillas de ese océano: asunto imposible en la realidad, pero absolutamente plausible en la coherencia interna del texto, donde a cada instante, se nos dan señas que ese espacio real se ha convertido, se ha trastocado en un espacio irreal e interior donde no existen las fronteras ni las distancias:

“(...) No, ese perro que ladra al sol caído no ladra en el Monturrio de Moguer, ni cerca de Carmona de Sevilla, ni en la calle Torrijos de Madrid; ladra en Miami, Coral Gables, La Florida, y yo lo estoy oyendo allí, allí, no aquí, no aquí, allí, allí (...)” (Jiménez, Espacio 19). 
Ese perro ladra entonces en la imaginación o en el recuerdo del que escribe, pero ladra en un espacio irreal, el espacio del poema que, a su vez, continuamente comunicará esa idea: el poeta escribe, crea, canta y el lector es seducido, llevado, deslumbrado e iniciado en el mundo propuesto (el espacio propuesto) por el poeta.

Los temas se sucederán cíclicos y algunos conducirán y contendrán a los otros -el mentado sistema de "cajas chinas"- como si un círculo abarcase al otro y así sucesivamente, pero no solo conteniéndolo, sino, también, uniéndolo. Desde un punto de vista gráfico, el poema se despliega como una espiral de círculos concéntricos apoyados en el eje del yo, del hablante que propone su viaje personal en que la temporalidad (paso, presente, futuro) no tiene un sentido lógico, como tampoco, ya lo he dicho, la espacialidad real, concreta, divisoria. Por el contrario, tiempo ${ }^{9}$ y espacio imaginarios serán los puntos de apoyo para la generación del "canto" (y, subrayo, una vez más, la idea, el concepto musical que existe aquí detrás: el hablante dice "canto", no texto, no poema, no discurso. Música más que poesía).

Frente a esta diversidad (que puede dar origen a una multitud de posibles interpretaciones y de "subinterpretaciones") es labor obligatoria del especialista registrarla y describirla: desgraciadamente, por su vastedad, no es éste el lugar para dar acabada cuenta de cada uno de estos tópicos, aunque sí, al menos, es preciso enumerarlos apostillando algunas de las particularidades esenciales de cada uno de ellos.

Independientemente del tema del espacio, de la anulación del que consideramos "espacio real" e, incluso, del "tiempo real", la espiral conductora del hablante nos llevará a una serie, a una "Suite" 10 de otros temas que son relevantes a la hora de dimensionar el poema con justicia. Estos temas o tópicos pueden enumerarse básicamente en los siguientes:

\section{Tema de Dios o de la religiosidad.}

2. Tema del amor.

3. Tema de la naturaleza.

4. Tema de la poesía.

5. Tema de la muerte y de la trascendencia.

A su vez, se encontrarán una serie de subtemas o temas contenidos dentro de estos temas (unidades menores que "alimentan" a unidades de contenido más importantes):

1. Tema de la música (Relacionado con la naturaleza, la armonía, los pájaros y, evidentemente, con la poesía: "el canto").

9 No debe olvidarse el importante libro autobiográfico Tiempo, que, en ese entonces, Juan Ramón escribía paralelamente a Espacio y que debe ser un complemento para la lectura del poema aquí analizado.

${ }^{10}$ Lo menciono también con la intención de considerarla, explícitamente, como una forma musical. 
2. Tema del lenguaje (Y su oposición a la armonía entre los hombres. El lenguaje de la naturaleza es perfecto, comunica, vincula. El lenguaje de los hombres los enfrenta entre sí, los separa y los enfrenta a la naturaleza, pues no conocen -o han olvidadosu lenguaje. También ha de considerarse la oposición entre el lenguaje entendido como sólo palabras (literatura) y el de la verdadera comunicación (la poesía, la naturaleza).

3. Tema de Abelardo y Eloísa (En clara conexión con el tema del amor y de la absoluta necesidad de tener y sostener lealmente un ideal, sin importar las circunstancias y con todas las renuncias que sean necesarias).

4. Tema o tópico del "Paraíso perdido" (Y su relación con el tema de la naturaleza olvidada por el hombre. El paraíso existe pero son los seres humanos quienes lo han abandonado).

5. Tema de la unidad (Vinculado con la trascendencia de la vida y del pensamiento del hombre, con la naturaleza, con la necesidad y presencia de Dios y con la poesía. Este subtema será "obligado" o de "apoyatura" a lo largo de todo el texto).

Es fundamental entender cómo se crea una relación sutil, aunque firme, entre las distintas unidades de sentido o "capas" que el hablante propone en el poema: relación que implica una idea en la otra, pero que, a la vez, profundiza en la temática específica de la que se habla.

\section{DESCRIPCIÓN DE LOS TEMAS ESENCIALES DE ESPACIO}

EI tema de Dios o de la religiosidad es el primero que inmediatamente aparece evidente ante el lector. La frase del "Fragmento Primero", "Los dioses no tuvieron más sustancia que la que tengo yo" atrapa y hace que el receptor entienda que el texto abordará claramente asuntos de orden trascendente o metafísico, a la par de constatar su humanidad y la sintonía de ésta con la divinidad. Por otro lado, hay constantes referencias a un cierto panteísmo que no se opone o contradice en absoluto con la visión del Dios monoteísta o, incluso, cristiano. Al contrario, como San Juan de la Cruz al ver las criaturas de su Cántico Espiritual, Juan Ramón al contemplar a Dios en todas las cosas ve su infinita sabiduría y la perfección de Su Obra. La mujer como creadora, como dadora de vida (más perfecta que el hombre); el pájaro, símbolo del canto, de la poesía, de la belleza; la naturaleza entera en su equilibrio maravilloso, hacen que el hablante pueda aferrarse a una esperanza de continuar, de trascender, pues se posibilita la existencia de un "Más Allá" (a pesar de que Dios sea visto en la actualidad como un Dios lejano "preocupado por tanta menudencia que le piden"). Finalmente se insta al lector y a la humanidad entera a "echarse a Dios" (casi como anacoretas iluminados o como místicos), es decir, entregarse a lo divino con la fe de "ser la eternidad" y "hacer la eternidad":

“(...) ¡Espacio y tiempo y luz en todo yo, en todos y yo y todos! ¡Yo con la inmensidad! Esto es distinto; nunca lo sospeché y ahora lo tengo. Los caminos son sólo 
entradas o salidas de luz, de sombra, sombra y luz; y todo vive en ellos para que sea más inmenso yo, y tú seas. ¡Qué regalo de mundo, qué universo inmenso, dentro, fuera de ti, segura inmensidad! Imágenes de amor en la presencia concreta; suma gracia y gloria de la imagen (sic.), ¿vamos a hacer eternidad? ¡Vosotras, yo, podemos crear la eternidad una y mil veces, cuando queramos! ¡Todo es nuestro y no se nos acaba nunca!" (Jiménez, Espacio 30).

El tópico amoroso o el tema del amor, tan caro al poeta andaluz, es recordado a través de distintos subtemas, aunque es una trama constante en todo el fluir del discurso. La historia ya conocida de Abelardo y Eloísa entrega la clave de lo que Juan Ramón propone: el ideal absoluto, la necesidad imperiosa de él y la imposible renuncia que éste implica. El amor, junto al canto, a la poesía, es una resonancia permanente en el poema: tras cada palabra se esconde la necesidad del amor y su importancia para relacionarse con los otros y con el mundo. Aún así, el hombre (el ser masculino) es visto como un necio, como un científico o un intelectual (frío, displicente, racional) que no comprende el ideal o el sustrato de las cosas (y también de la verdadera naturaleza). Por el contrario, la mujer (personificada en Eloísa) es el ideal mismo que en su femineidad comprende y "es" la poesía. Ella logra completar el lugar, el espacio, que el hombre no llena, que no abarca y que, por desgracia, nunca logrará entender:

“(...) Amor el de Eloísa; ¡qué ternura, qué sencillez, qué realidad perfecta! Todo claro y nombrado con su nombre en llena castidad. Y ella, enmedio [Sic] de todo, intacta de lo bajo entre lo pleno. Si tu mujer, Pedro Abelardo, pudo ser así, el ideal existe, no hay que falsearlo. Tu ideal existió; ¿por qué lo falseaste, necio Pedro Abelardo? Hombres, mujeres, hombres, hay que encontrar el ideal, y dí [Sic], qué eres tú ahora y dónde estás? (...)" (Jiménez, Espacio 21).

El tema de la naturaleza es materia constante de preocupación, fuente de iluminación y receptora del hablante en sus meditaciones a lo largo de todo el texto (en una mirada que he señalado como profética en cuanto propone una necesaria unión entre el hombre y su entorno; en cuanto establece la idea de un indispensable equilibrio y es un ejemplo de perfección, adelantándose Jiménez al nacimiento de la ecología como disciplina científica y preocupación global). La simbología expresada en torno a este tema (las flores, por ejemplo, como símbolo de los deseos del ser humano), sus atribuciones (el universo natural es más humano que el hombre), su presencia ineludible y su oposición a la ciencia (entendida solo como una vana pretensión humana de querer entender al mundo) lo hacen protagonista y, hasta visto casi como un personaje, en todo el poema Espacio. Por otro lado, hay una denuncia y una crítica a la actitud de los habitantes del planeta frente al elemento natural. El hombre destruye, aniquila, la naturaleza crea, da vida. El hombre ha "perdido" su paraíso por la tecnología, por la ciencia y, lo que es más grave, ha perdido su condición de "ser natural" que las plantas y los animales (y aquí vale el ejemplo del perro, que entiende su entorno y lo ama) jamás han abandonado u olvidado. El poeta es naturaleza y pertenece a ella: 
“(...) Y soy un dios sin espada, sin nada de lo que hacen los hombres con su ciencia; sólo con lo que es producto de lo vivo, lo que se cambia todo; sí, de fuego o de luz, luz. ¿Por qué comemos y bebemos otra cosa que luz o fuego? Como yo he nacido en el sol, y del sol he venido aquí a la sombra, ¿soy de sol, como el sol alumbro?, y mi nostaljia, como la de la luna, es haber sido sol de un sol un día y reflejado sólo ahora. Pasa el iris cantando como canto yo. Adiós iris, volveremos a vernos, que el amor de todo, cómo se me ha hecho en el sol, con el sol, en mí conmigo? (...)" (Jiménez, Espacio 10-11).

La poesía será otro de los temas esenciales de Espacio, su presencia, al igual que en el caso de la naturaleza, será permanente y, más aún, constituirá otra de las "tramas" constantes que utiliza Juan Ramón como crisol creador de tópicos y preocupaciones en el transcurso de su largo monólogo lírico. La poesía asociada a la naturaleza (la imagen del pájaro que entra en el aposento del poeta renovando su canto, su obra, que es, se puede decir, imitación y diálogo; la imagen misma del ruiseñor y su canto, la presencia permanente de intertextos poéticos de varios poetas como François Villon o William B. Yeats, por ejemplo) y, también la poesía como "escape", como fluir y, aunque suene a paradoja, como la única forma de enfrentar al mundo, ese mundo de "los otros", entregarán la idea sustantiva del autor donde el hombre puede, logra conectarse con la trascendencia a través de la poesía (que no del idioma, "tan confuso", en palabras de Jiménez). La palabra, entonces, será útil e indispensable para la comunicación con el universo, con Dios, con la naturaleza, pero solo la palabra poética o la escrita o dicha por el poeta, porque la palabra común, la "palabra silvestre" será para el autor un símil de la confusión, de vacío, soledad y aislamiento. Por otro lado, la literatura será "menospreciada", no la narrativa, o el ensayo o la dramaturgia en especial, sino lo que se puede calificar como "literatoso", esa literatura por la literatura, como nos dice en estas líneas de Espacio: "que bueno es dejar un libro a medias sobre un banco, sin terminar de leerlo. Y hay que darle una lección a quien lo quiere terminar..." afirma con propiedad. La literatura será vista, al igual que el idioma, como una fuente de ruido, de trágica incomunicación ("todo lo demás es literatura" al decir de Paul Verlaine en su "Arte Poética"), de allí la aspiración de Jiménez, ya mencionada, a "ser poesía y no poeta". Es la poesía (el canto) la clave, como la música, del lenguaje universal. Véase este hermoso episodio, antes aludido, donde el canto del poeta y el canto del pájaro devienen una misma cosa:

“(...) ¿El canto? ¡El canto, el pájaro otra vez! ¡Ya estás aquí, ya has vuelto, hermosa, hermoso, con otro nombre, con tu pecho azul, gris cargado de diamante! ¿De dónde llegas tú, tú en esta tarde gris con brisa cálida? ¿Qué dirección de luz y amor sigues entre las nubes de oro cárdeno? Ya has vuelto a tu rincón verde, sombrío. ¿Cómo tú, tan pequeño, dí, lo llenas todo y sales por el más? Sí, sí, una nota de una caña, de un pájaro, de un niño, de un poeta, lo llena todo y más que el trueno. El estrépito encoje, el canto agranda. Tú y yo, pájaro, somos uno; cántame, canta tú, que yo te oigo, que mi oído es tan justo por tu canto. Ajústame tu canto más a este oído mío que espera que lo llenes de armonía, ¡Vas a cantar! toda otra primavera, vas a cantar (...)" (Jiménez, Espacio 26-27). 
Por último, cabe señalar el tema de la muerte y de la trascendencia que, sin duda, el poeta elabora con mayor profundidad en el "Fragmento Tercero". Aquí, hacia el final del fragmento inicial, se invita al lector, o mejor, se lo conmina, a entregarse a la eternidad pero haciéndola, es decir, construyendo la eternidad desde su propia vida y en el tiempo presente (punto de apoyo clave para el poeta,

“(...) ¿Vamos a hacer la eternidad, vamos a hacer la eternidad, vamos a ser eternidad, vamos a ser la eternidad? ¡Vosotras, yo, podemos crear la eternidad una y mil veces, cuando queramos! ¡todo es nuestro y no se nos acaba nunca! ¡Amor, contigo y con la luz todo se hace, y lo que haces, amor, no acaba nunca! (...)" (Jiménez, Espacio $30)$.

Una eternidad construida sobre la base del amor, de la comprensión, de la poesía. Una eternidad de todos, viva y no agonizante: eternidad que llama desde el presente, insisto, para poder ser haciéndose... Eternidad, como la vida, antagonista de la figura de la muerte o del fin: llena de ilusión, de ideal, contraria a la solemnidad de las palabras huecas o a todo lo que puede ser entendido como marmóreo (al menos en este "Fragmento Primero"). Una eternidad, como última consideración, que hace ver muy vivamente a Juan Ramón Jiménez, lejos, lejísimo, de los pobres y hasta denigrantes clisés con los que muchos lectores, críticos y hasta poetas han menospreciado buena parte de su "Obra". Este Juan Ramón, el de Espacio y el de En el otro costado que no se resigna jamás a perder el lugar inconmensurable de la imaginación, que no renuncia, ni por un momento, al feliz tormento que arranca de la creación.

\section{BIBILIOGRAFÍA}

De Albornoz, Aurora. "Estudio de la obra. Espacio: Culminación, recapitulación y crítica de la "Obra"” en Jiménez, Juan Ramón. Espacio. Edición a cargo de Aurora de Albornoz. Madrid: Editora Nacional, 1982.

“Espacio". En Rico, Francisco. Historia y Crítica de la Literatura Española. Época Contemporánea 1914-1939. Vol. III (Víctor García de la Concha, editor). Barcelona: Editorial Crítica, 1984.

Jiménez, Juan Ramón. Almas de Violeta. Madrid: Tipografía Moderna, 1900.

Ninfeas. Madrid: Tipografía Moderna, 1900.

Diario de un poeta reciéncasado. Madrid: Editorial Calleja, 1917.

Poesías escojidas (sic.). New York: The Hispanic Society of America, 1917.

Segunda Antolojía Poética (sic.). Madrid: Editorial Espasa-Calpe, 1922.

Romances de Coral Gables. México: Editorial Stylo, 1948.

Animal de fondo. Buenos Aires: Editorial Pleamar, 1949.

Tercera Antolojía Poética (sic.). Madrid: Editorial Biblioteca Nueva, 1957. 
Antolojía Jeneral (sic.) en prosa (1898-1954). Edición de Ángel Crespo y Pilar Gómez Bedate. Madrid: Editorial Biblioteca Nueva, 1981. 1982.

Espacio. Edición a cargo de Aurora de Albornoz. Madrid: Editora Nacional,

Morales, Andrés. En el otro costado, una lectura de Espacio de Juan Ramón Jiménez, conferencia dictada en la Pontificia Universidad Católica de Valparaíso en el Instituto de Literatura y Ciencias del Lenguaje en octubre de 1995 y publicada en el libro Cuadernos Hispánicos I. Eduardo Godoy Gallardo editor. Valparaíso: Universidad Católica de Valparaíso, 1997. 